\title{
Persistent improvement in synaptic and cognitive functions in an Alzheimer mouse model after rolipram treatment
}

\author{
Bing Gong, ${ }^{1,2}$ Ottavio V. Vitolo,2 Fabrizio Trinchese,1,3 Shumin Liu,1,3 Michael Shelanski,2 \\ and Ottavio Arancio 1,2,3,4 \\ ${ }^{1}$ The Center for Dementia Research, Nathan Kline Institute for Psychiatric Research, Orangeburg, New York, USA. 2Department of Pathology \\ and the Taub Institute for Research on Alzheimer's Disease and the Aging Brain, Columbia University, New York, New York, USA. \\ ${ }^{3}$ Department of Psychiatry and ${ }^{4}$ Department of Physiology and Neuroscience, New York University School of Medicine, New York, New York, USA.
}

\begin{abstract}
Evidence suggests that Alzheimer disease (AD) begins as a disorder of synaptic function, caused in part by increased levels of amyloid $\beta$-peptide 1-42 (A $\beta 42)$. Both synaptic and cognitive deficits are reproduced in mice double transgenic for amyloid precursor protein (AA substitution $\mathrm{K} 670 \mathrm{~N}, \mathrm{M671L}$ ) and presenilin-1 (AA substitution M146V). Here we demonstrate that brief treatment with the phosphodiesterase 4 inhibitor rolipram ameliorates deficits in both long-term potentiation (LTP) and contextual learning in the double-transgenic mice. Most importantly, this beneficial effect can be extended beyond the duration of the administration. One course of long-term systemic treatment with rolipram improves LTP and basal synaptic transmission as well as working, reference, and associative memory deficits for at least $\mathbf{2}$ months after the end of the treatment. This protective effect is possibly due to stabilization of synaptic circuitry via alterations in gene expression by activation of the cAMP-dependent protein kinase (PKA)/cAMP regulatory element-binding protein (CREB) signaling pathway that make the synapses more resistant to the insult inflicted by $A \beta$. Thus, agents that enhance the CAMP/PKA/CREB pathway have potential for the treatment of AD and other diseases associated with elevated $A \beta 42$ levels.
\end{abstract}

\section{Introduction}

Alzheimer disease $(\mathrm{AD})$ is a progressive neurodegenerative disorder characterized by mild cognitive impairment at its onset followed by deficits in multiple cortical functions in later stages. It begins as a disorder of synaptic function (1) caused in part by increased levels of amyloid $\beta$-peptide 1-42 (A $\beta 42)$. Over time, synaptic dysfunction is followed by cell death and irreversible brain damage (2-5). Recently we demonstrated that sublethal levels of $A \beta 42$ inhibit activation of the cAMP/cAMP-dependent protein kinase/cAMP regulatory element-binding protein (cAMP/PKA/CREB) pathway in hippocampal cultures and that this inhibition is responsible for impairment of long-term potentiation (LTP) of the CA1 hippocampal region (4), a physiological correlate of synaptic plasticity that is thought to underlie learning and memory (6). Rolipram, a specific inhibitor of the phosphodiesterase type 4 (PDE4) isoform, is able to restore the cAMP/PKA/CREB pathway activity and LTP (4).

Manipulations of the cAMP signaling pathway can have beneficial effects in the context of age-related memory loss (7). Rolipram has been shown to reverse memory deficits produced by pharmacological blockade, such as $N$-methyl-D-aspartate (NMDA) (8), or muscarinic blockade $(9,10)$, and those induced by MAPK

Nonstandard abbreviations used: $A \beta$, amyloid $\beta$-peptide; $A \beta 42, A \beta 1-42 ; A D$, Alzheimer disease; $\mathrm{AL}$, adjacent quadrant to the left; $A P P$, amyloid precursor protein; $\mathrm{AR}$, adjacent quadrant to the right; $\mathrm{BST}$, basal synaptic transmission; CREB, cAMP regulatory element-binding protein; CS, conditioned stimulus; fEPSP, field excitatory postsynaptic potential; L-LTP, late-phase LTP; LTP, long-term potentiation; NMDA, $N$-methyl-D-aspartate; OQ, opposite quadrant; PDE, phosphodiesterase; phospho-, phosphorylated; PKA, cAMP-dependent protein kinase, PS1, presenilin-1; TQ, target quadrant; US, unconditioned stimulus.

Conflict of interest: The authors have declared that no conflict of interest exists.

Citation for this article: J. Clin. Invest. 114:1624-1634 (2004).

doi:10.1172/JCI200422831. inhibitors (11). In addition, the PDE4 inhibitor enhances LTP and long-term memory retention in both young and aged rats (12) and improves memory in animal models of cerebral ischemia $(10,13)$ and Rubinstein-Taybi syndrome (14). Agents such as caffeine that have nonspecific phosphodiesterase inhibitory activity as well as other activities can also improve cognition in specific conditions (15). Finally, there is evidence that while PKA activation in the hippocampus improves memory, inhibition of PKA in the prefrontal cortex improves memory and PKA activation impairs prefrontal function in both aged rats and monkeys (16).

Based on these findings, we asked whether rolipram could exert beneficial effects in the brains of mice carrying both the mutant amyloid precursor protein (APP) $(\mathrm{K} 670 \mathrm{~N}, \mathrm{M} 671 \mathrm{~L})$ and presenilin-1 (PS1) (M146L) transgenes (APP/PS1 mice), an animal model of amyloid deposition that partially reproduces the cognitive deficits that occur in $\operatorname{AD}$ patients $(17,18)$. These mice display impaired LTP, spatial working memory, and contextual learning as early as 3-4 months of age, and they show deficits in basal synaptic transmission (BST) and spatial reference memory after 5-6 months of age (19).

\section{Results}

Acute effects of rolipram on synaptic function in hippocampal slices of APP/ PS1 mice. In the first series of experiments we tested whether the beneficial effect of rolipram on the LTP impairment induced by acute treatment of hippocampal slices with $A \beta$ (4) was also present in slices obtained from 3-month-old APP/PS1 mice, when synaptic plasticity impairment is just starting. BST was determined by measurement of the slope of the field excitatory postsynaptic potential (fEPSP) at increasing stimulus intensity in APP/PS1 and WT mice. We found no difference in BST among the different groups (Figure 1A) (19). The slope of the input-output curve at a stimulation 

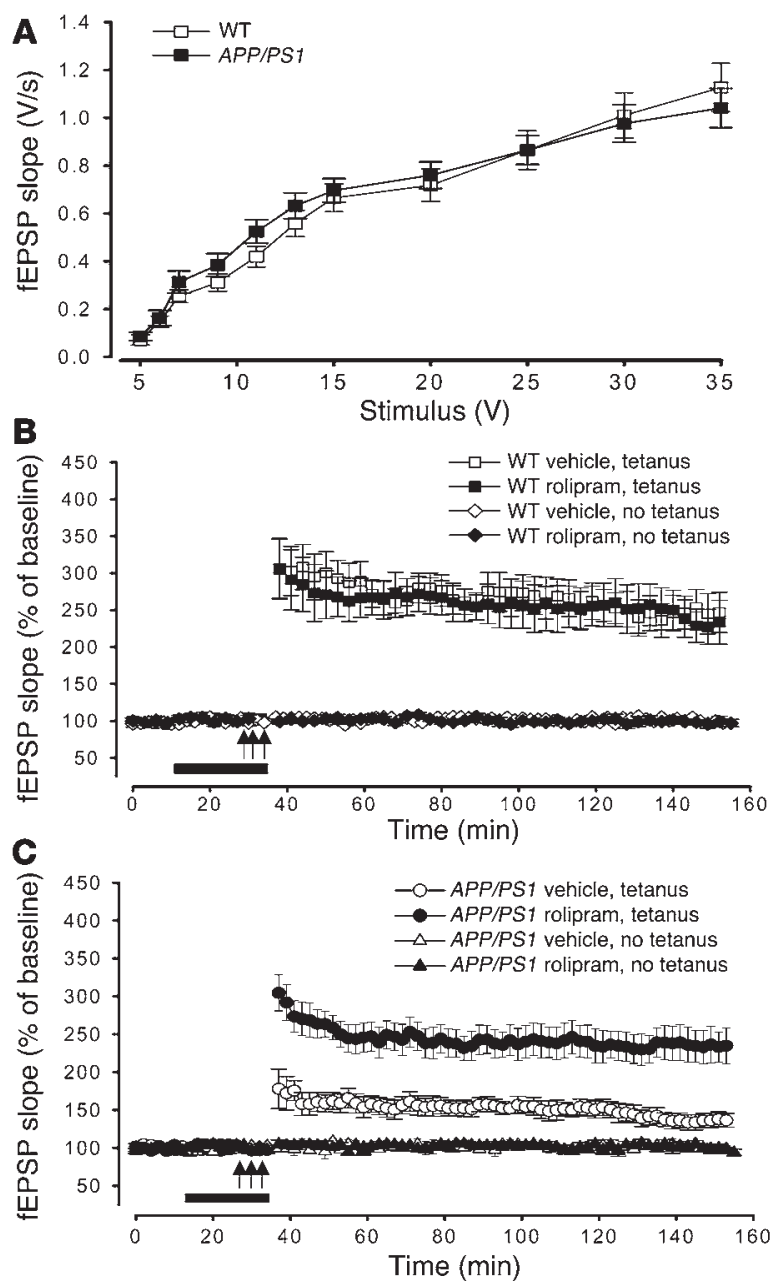

intensity equal to $35 \mathrm{~V}$ in $A P P / P S 1$ mice was about $108 \%$ that of WT littermates $(A P P / P S 1$ mice, $1.13 \pm 0.1 \mathrm{~V} / \mathrm{s}, n=12$ slices from 10 males; WT mice, $1.04 \pm 0.08 \mathrm{~V} / \mathrm{s}, n=15$ slices from 13 males). Two-way ANOVA showed no difference between double-transgenic mice and their littermate controls $[\mathrm{F}(1,25)=0.091, P>0.05]$. Similar results were obtained when the fEPSP slope was plotted versus the amplitude of the fiber afferent volley (data not shown). Hippocampal slices were then perfused with rolipram $(1 \mu \mathrm{M})$ for 20 minutes before induction of late-phase LTP (L-LTP) through tetanic stimulation of the Schaeffer collateral pathway. Potentiation in rolipram-treated $A P P / P S 1$ slices was far greater than that in vehicle-treated $A P P / P S 1$ slices (levels of LTP in rolipram-treated $A P P / P S 1$ mice were equal to about $93 \%$ that of vehicle-treated WT littermates at 120 minutes after tetanus, versus about $54 \%$ for vehicle-treated APP/PS1 mice: rolipram-treated APP/PS1 mice, $230.46 \pm 20.86 \%$ at 120 minutes after tetanus, $n=13$ slices from 11 males; vehicle-treated $A P P / P S 1$ mice, $133.34 \pm 8.87 \%, n=12$ slices from 10 males; vehicle-treated WT mice, $246.37 \pm 21.81 \%, n=13$ slices from 11 males; Figure 1, B and C). Two-way ANOVA revealed a significant difference between the $2 A P P / P S 1$ groups $[F(1,23)=$ $12.48, P<0.001]$, and planned comparisons showed that the groups were significantly different at each time point after the tetanus $(P<0.001)$. On the other hand, rolipram did not change the amplitude of L-LTP in hippocampal slices of WT mice compared with that of WT slices treated with vehicle alone $[\mathrm{F}(1,26)=0.87$,

\section{Figure 1}

Rolipram reverses the impairment of L-LTP in the CA1 region of slices from 3-month-old APP/PS1 mice. (A) BST is similar in 3-monthold APP/PS1 animals and WT littermates. Summary graph of field input-output relationship for different stimulation intensities (5-35 V) $[\mathrm{F}(1,25)=0.091, P>0.05]$. (B) Summary graph showing that 20 minutes of treatment with rolipram does not affect L-LTP and baseline transmission in WT mice $[\mathrm{F}(1,26)=0.87, P>0.05]$. (C) Summary graph showing that rolipram abrogates L-LTP impairment in APP/PS1 mice without affecting basal neurotransmission. These experiments were interleaved with those of WT mice $[\mathrm{F}(1,23)=12.48, P<0.001]$. Arrows indicate time and pattern of the tetani.

$P>0.05$; Figure 1B]. Levels of LTP at 120 minutes after tetanus were about $95 \%$ those of vehicle-treated WT slices $(234.60 \pm 20.32 \%$, $n=15$ slices from 13 males). Rolipram had no effect on basal synaptic responses in slices from $A P P / P S 1$ mice $[\mathrm{F}(1,9)=1.74, P>0.05]$ or WT littermates $[\mathrm{F}(1,11)=2.09, P>0.05]$ either during its application or 120 minutes after the end of the application in experiments in which no tetanic stimulation was applied (about $96 \%$ of vehicletreated slices in rolipram-treated APP/PS1 slices, versus about $98 \%$ in vehicle-treated $A P P / P S 1$ slices and about $97 \%$ in rolipram-treated WT slices: $A P P / P S 1,99.98 \pm 2.86 \%$ in rolipram-treated slices, $n=5$ slices from 3 males, versus $102.31 \pm 4.25 \%$ in vehicle-treated slices, $n=6$ slices from 4 males; WT, $101.65 \pm 7 \%$ in rolipram-treated slices, $n=7$ slices from 4 males, versus $103.75 \pm 6.28 \%$ in vehicle-treated slices, $n=6$ slices from 5 males; Figure 1, B and C).

Acute effects of rolipram on the cognitive function of APP/PS1 mice. Because the electrophysiological studies showed that rolipram ameliorated L-LTP deficits in 3-month-old double-transgenic mice, we then tested whether it was capable of reversing behavioral impairment in these animals. Rolipram is a compound with a very short half-life ( 3 hours) that readily passes through the bloodbrain barrier, is rapidly cleared by the kidneys, and does not accumulate in the tissues (20). Our initial studies examined the effects of acute administration of rolipram on hippocampus-dependent memory. We used 2 different tests of hippocampus-dependent memory: fear-conditioning learning and spatial working memory. These tests involve different forms of explicit learning and have been found to be impaired at the age of 3 months in the doubletransgenic mice (19). The fear-conditioning learning paradigm depends on the hippocampus and amygdala. The hippocampus, in particular, is indispensable for contextual fear conditioning (21), a form of associative learning in which mice must associate a neutral stimulus with an aversive one. This type of cognitive test is more rapid than other behavioral tasks that require multiple days of training and testing. In a series of preliminary experiments, we tested whether the APP/PS1 and WT mice had different perceptions of an electric shock. We found that the shock threshold was the same for mice of the different genotypes (data not shown). Next we examined contextual fear conditioning. APP/PS1 and WT littermates 3 months of age were subjected to a standard fear-conditioning paradigm (22). Thirty minutes after injection of rolipram, the animals were placed in a novel context (fear-conditioning box) and were exposed to a tone (conditioned stimulus [CS]) paired with a mild foot shock (unconditioned stimulus [US]) (training phase of the fear conditioning). Conditioning was assessed 24 hours later by measurement of "freezing" behavior - the absence of all movement except for that necessitated by breathing - in response to the context (contextual conditioning) or the auditory 

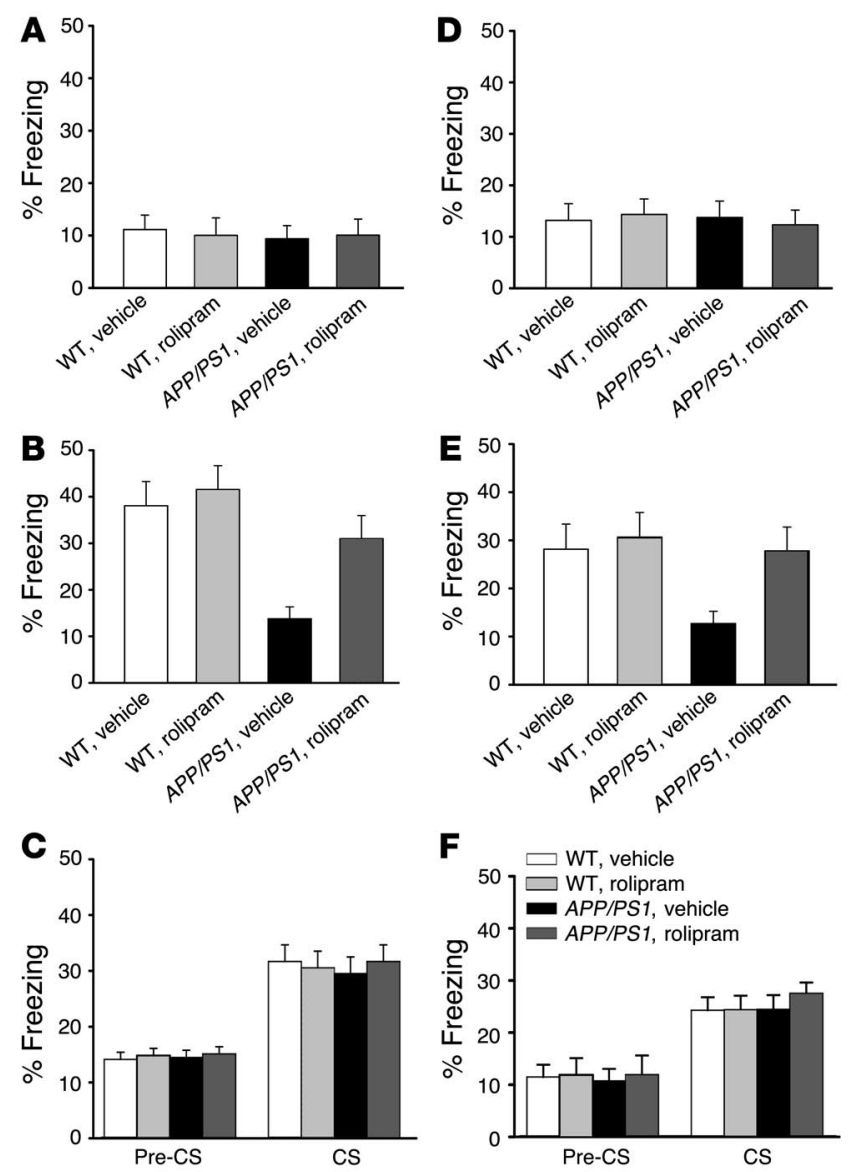

cue (CS) within a completely different context (cued conditioning). During the training phase, we found no difference in the freezing of $A P P / P S 1$ mice treated with rolipram $(0.03 \mathrm{mg} / \mathrm{kg}$ s.c. $)$ or with vehicle 30 minutes before performing the test compared with that of rolipram- or vehicle-treated WT littermates (Figure 2A). Twoway ANOVA followed by the Bonferroni test revealed no significant difference between the 4 groups $[\mathrm{F}(1,46)=0.14, P>0.05]$. Twentyfour hours later we found a decrease in the freezing time of vehicletreated APP/PS1 mice compared with that of vehicle-treated WT littermates in contextual conditioning (vehicle-treated APP/PS1 mice demonstrated about $36 \%$ that of vehicle-treated WT mice; $13.80 \pm 2.56 \%$ in $A P P / P S 1, n=12,8$ males plus 4 females, versus $38.07 \pm 5.22 \%$ in WT littermates, $n=12$, 8 males plus 4 females; Figure $2 \mathrm{~B}$ ). However, the freezing time was increased in APP/PS1 mice after the injection of rolipram (rolipram-treated APP/PS1 mice demonstrated about $81 \%$ that of vehicle-treated WT mice: $31.03 \pm 4.94 \%, n=12,8$ males plus 4 females; Figure $2 \mathrm{~B})$. The freezing responses of rolipram-treated $A P P / P S 1$ mice were similar to those of vehicle-treated WT littermates. WT animals treated with rolipram showed a nonsignificant increase in freezing (about $109 \%$ that of vehicle-treated WT mice: $41.56 \pm 5.13 \%, n=14,10$ males plus 4 females), probably because maximal levels of memory are already induced in vehicle-treated WT mice after the training session, as has been found both in Drosophila and in mice (23). Two-way ANOVA followed by the Bonferroni test revealed a statistically significant difference between the 4 groups $[\mathrm{F}(1,46)=10.57$, $P<0.01]$. Post-hoc analysis showed a statistically significant difference between vehicle-treated APP/PS1 and WT littermates

\section{Figure 2}

Rolipram injections improve contextual conditioning performance both in 3-month-old APP/PS1 mice and in 6-month-old double-transgenic mice that had received injections for 3 weeks at the age of 3 months. (A) Three-month-old APP/PS1 and WT littermates treated with rolipram or vehicle 30 minutes prior to testing show no difference in immediate freezing in the training chamber $[\mathrm{F}(1,46)=0.14, P>0.05]$. (B) Three-month-old vehicle-treated APP/PS1 mice show reduced freezing responses compared with vehicle-treated WT littermates during contextual fear conditioning performed 24 hours after training. Injection of rolipram the day before ameliorates the deficit in freezing responses in APP/PS1 mice. Rolipram has no effect on the freezing responses in WT mice $[\mathrm{F}(1,46)=10.57, P<0.01]$. (C) Three-month-old APP/PS1 and WT littermates treated with rolipram or vehicle show similar freezing during cued conditioning [both in the pre-CS group, $F(1,46)=0.57$, $P>0.05$, and in the CS group, $\mathrm{F}(1,46)=0.32, P>0.05]$. (D) Six-monthold APP/PS1 and WT littermates previously treated with daily injections of rolipram or vehicle show no difference in immediate freezing in the training chamber $[F(1,47)=0.79, P>0.05]$. (E) Contextual fear conditioning performed 24 hours after training shows a reduction in freezing responses in 6-month-old APP/PS1 mice pretreated with vehicle compared with that of WT littermates previously treated with vehicle. Pretreatment with rolipram ameliorates the deficit in freezing responses in APP/PS1 mice. Rolipram has no effect on the freezing responses in WT mice $[\mathrm{F}(1,47)=6.68, P<0.05]$. (F) Six-month-old APP/PS1 and WT littermates previously treated with rolipram or vehicle show similar freezing during cued conditioning [both in the pre-CS group, $\mathrm{F}(1,47)=0.07, P>0.05$, and in the CS group, $\mathrm{F}(1,47)=0.34, P>0.05]$.

$(P<0.01)$ as well as between rolipram-treated and vehicle-treated $A P P / P S 1$ mice $(P<0.01)$. We next tested cued fear conditioning, a hippocampus-independent task (21), and did not find a difference in freezing behavior among the 4 groups [both in the pre-CS group, $\mathrm{F}(1,46)=0.57, P>0.05$, and in the CS group, $\mathrm{F}(1,46)=0.32$, $P>0.05$; Figure $2 \mathrm{C}]$. This result suggests that the amygdala, which is involved mainly in cued conditioning, is not impaired in these mice. These findings are also consistent with previous results in other models of $\operatorname{AD}(24,25)$ and indicate that APP/PS1 mice have a selective hippocampus-dependent impairment in associative learning. Most important, they demonstrate that rolipram is capable of restoring normal associative learning in APP/PS1 mice.

Next, we tested whether rolipram is capable of improving the spatial working memory impairment present in the APP/PS1 mice at 3 months of age. Spatial working memory is a type of shortterm memory that can be studied with the radial-arm water maze test. This task has proven informative in the analysis of other transgenic models of $\operatorname{AD}(19,26,27)$ as well as animals in which genes involved in synaptic plasticity have been knocked out (28) and has been shown to depend upon hippocampal function (29). In contrast to the improvement seen in LTP and in the contextual fear-conditioning paradigm, acute rolipram treatment (30 minutes before the test) did not induce significant improvement in the performance of $A P P / P S 1$ mice in the radial-arm water maze [2-way ANOVA, $\mathrm{F}(1,29)=0.27, P>0.05$, compared with vehicle-treated $A P P / P S 1$ mice; see Supplemental Figure 1; supplemental material available at http://www.jci.org/cgi/content/full/114/10/1624/ DC1]. Rolipram-treated APP/PS1 mice averaged $5.8 \pm 0.56$ errors in the first acquisition trial (A1), $3.4 \pm 0.43$ errors by the fourth consecutive trial (A4), and $4.6 \pm 0.40$ errors by the recall trial (R) performed 30 minutes after trial A4 $(n=18,14$ males plus 4 females). Vehicle-treated $A P P / P S 1$ mice averaged $5.81 \pm 0.75$ errors in trial A1, $3.79 \pm 0.63$ errors in trial A4, and $4.9 \pm 0.69$ errors in 

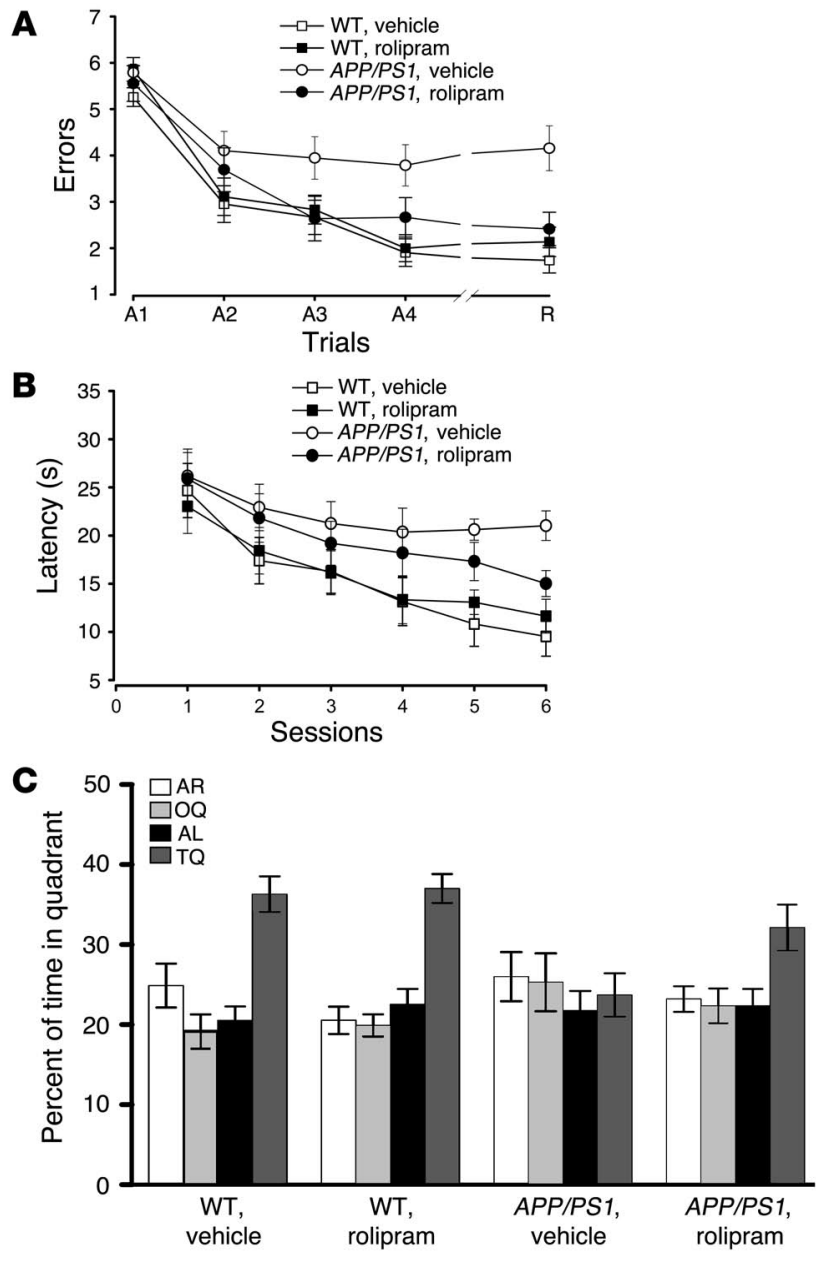

the recall trial $\mathrm{R}$ ( $n=13,10$ males plus 3 females). Rolipram did not alter the performance of WT animals compared with that of WT treated with vehicle alone [rolipram: A $1=5.8 \pm 0.68$ errors, $\mathrm{A} 4=2.74 \pm 0.47$ errors, $\mathrm{R}=2.8 \pm 0.45$ errors, $n=12,8$ males plus 4 females; vehicle: $\mathrm{A} 1=5.5 \pm 0.58$ errors, $\mathrm{A} 4=2.6 \pm 0.44$ errors, $\mathrm{R}=2.6 \pm 0.41$ errors, $n=11,8$ males plus 3 females, $\mathrm{F}(1,21)=0.18$, $P>0.05$; see Supplemental Figure 1]. Two-way ANOVA showed a significant difference in the performance of vehicle-treated WT mice and that of vehicle-treated $A P P / P S 1$ littermates $[\mathrm{F}(1,22)=$ $5.65, P<0.05]$, and planned comparisons demonstrated that the 2 groups were significantly different at trial A4 $(P<0.05)$ and trial $\mathrm{R}$ $(P<0.01)$. These findings indicate impairment in spatial memory for platform location during both acquisition and retention of the task in the APP/PS1 mice. It is possible that overexpression of APP and $P S 1$ could cause impairments of vision, motor coordination, or motivation, any of which could lead to a deficit unrelated to memory in the radial-arm water maze task. If this were the case, rolipram would not be expected to have an effect. To control for this possibility, we tested all 4 groups of animals with the visible platform task. APP/PS1 and WT mice treated with rolipram or with vehicle showed no difference in the time needed to find the platform in this version of the task $[A P P / P S 1$ mice treated with rolipram, $26.81 \pm 3.02$ seconds in the first day of testing and $23.48 \pm 2.13$ seconds on the second day of testing; APP/PS1 mice treated with vehicle, $29.10 \pm 4.25$ seconds and $24.06 \pm 3.67 \mathrm{sec}-$ onds on the first and second days of testing, respectively; WT mice

\section{Figure 3}

Daily injections of rolipram for 3 weeks in 3-month-old APP/PS1 mice improve radial-arm water maze and Morris water maze performance in 6- to 7-month-old APP/PS1 mice. (A) Impairment of learning and memory during radial-arm water maze testing in APP/PS1 mice is ameliorated by previous treatment with rolipram. Rolipram does not affect the performance of WT mice. Two-way ANOVA revealed a significant overall difference between vehicle-treated APP/PS1 and WT littermates $[F(1,22)=13.53, P<0.01]$ as well as vehicle-treated and rolipram-treated $A P P / P S 1$ mice $[F(1,22)=4.89, P<0.05]$. (B) The performance of $A P P / P S 1$ mice in the Morris water maze is improved by previous treatment with rolipram. Two-way ANOVA showed no significant difference in the overall performance of rolipram-treated APP/PS1 mice compared with that of vehicle-treated APP/PS1 mice $[F(1,22)=0.36, P>0.05]$. However, planned comparisons of latency on each individual session revealed a significant difference between rolipram-treated APP/PS1 mice and vehicle-treated APP/PS1 mice in the sixth session $(P<0.05)$. (C) In the probe test, APP/PS1 mice previously treated with rolipram search significantly more time in the target quadrant, where the platform was located during training, than do vehicle-treated APP/PS1 littermates $(P<0.05)$. Rolipram has no effect on WT mice $(P>0.05)$.

treated with rolipram, $29.15 \pm 3.85$ seconds and $22.46 \pm 4.28 \mathrm{sec}-$ onds on the first and second days of testing, respectively; WT mice treated with vehicle, $28.07 \pm 2.42$ seconds and $23.04 \pm 3.15 \mathrm{sec}$ onds on the first and second days of testing, respectively; $\mathrm{F}(1,29)$ $=0.013$ for $A P P / P S 1$ mice treated with rolipram or with vehicle; $\mathrm{F}(1,21)=0.015$ for WT mice treated with rolipram or with vehicle; $P>0.05$ for both comparisons; data not shown]. There was also no difference in swimming speed among the groups $[A P P / P S 1$ mice treated with rolipram, $23.33 \pm 1.74 \mathrm{~cm} / \mathrm{s}, A P P / P S 1$ mice treated with vehicle, $21.09 \pm 1.83 \mathrm{~cm} / \mathrm{s}$, WT mice treated with rolipram, $22.75 \pm 1.67 \mathrm{~cm} / \mathrm{s}$, and WT mice treated with vehicle, $23.59 \pm 1.56$ $\mathrm{cm} / \mathrm{s} ; \mathrm{F}(1,52)=0.78 ; P>0.05$; data not shown]. Thus, defects in vision, motor coordination, or motivation were not responsible for the abnormal performance with the radial-arm water maze test. Taken together, the results of the experiments with the radial-arm water maze support the view that acute rolipram treatment does not immediately improve spatial working memory.

Persistent effects of rolipram on cognitive and synaptic functions in APP/ PS1 mice. To gain further insight into the effect of rolipram on cognitive and synaptic function, we examined whether long-term treatment with rolipram was capable of maintaining its protective effect against synaptic dysfunction and memory loss. In these experiments, both $A P P / P S 1$ and WT mice 3 months of age were injected s.c. with $0.03 \mathrm{mg} / \mathrm{kg} /$ day of rolipram for 3 weeks, then the treatment was stopped for $6-8$ weeks prior to testing. The mice were next subjected to a series of behavioral tests in the following experimental sequence: contextual conditioning for contextual learning, the radial-arm water maze for working memory, and the Morris maze for reference memory. Finally, the mice were sacrificed for electrophysiological studies of synaptic function. As in the acute experiments, we found no significant differences during the training phase of fear conditioning in the freezing behavior of the 4 groups of mice $[\mathrm{F}(1,47)=0.79 ; P>0.05$; Figure $2 \mathrm{D}]$. However, when the animals were reintroduced into the same context 24 hours after training, the freezing time was greatly increased in $A P P / P S 1$ mice that had been previously treated with rolipram compared with that of vehicle-treated $A P P / P S 1$ littermates (rolipram-treated APP/PS1 mice demonstrated about $98 \%$ that of vehicle-treated WT mice, versus about $45 \%$ for vehicle-treated 
APP/PS1 mice; rolipram-treated APP/PS1 mice, $27.79 \pm 4.94 \%$, $n=14,11$ males plus 3 females; vehicle-treated APP/PS1 mice, $12.71 \pm 2.55 \%, n=10,8$ males plus 2 females). Rolipram did not significantly increase the freezing time in WT littermates compared with that of WT mice treated with vehicle (about 108\% that of vehicle-treated WT mice; $30.65 \pm 5.12 \%, n=12$, 9 males plus 3 females, versus $28.15 \pm 5.22 \%, n=12,10$ males plus 2 females; Figure 2E). Two-way ANOVA followed by the Bonferroni test revealed a statistically significant difference among the 4 groups $[\mathrm{F}(1,47)=$ 6.68; $P<0.05]$. Post-hoc analysis showed a statistically significant difference between vehicle-treated APP/PS1 and WT littermates $(P<0.01)$, as well as between rolipram-treated and vehicle-treated $A P P / P S 1$ mice $(P<0.05)$. There were no significant differences between the 4 groups in the cued conditioning test $[24.48 \pm 4.31 \%$ versus $27.56 \pm 4.81 \%$ for $A P P / P S 1$ mice, and $24.29 \pm 5.05 \%$ versus $24.38 \pm 4.82 \%$ for $\mathrm{WT}$ mice; $\mathrm{F}(1,47)=0.34 ; P>0.05$; Figure $2 \mathrm{~F}]$.

The effects of 1 course of 3 weeks of treatment with rolipram on spatial working memory were next tested using the radial-arm water maze task. As expected, there was a significant difference between the number of errors made by vehicle-treated APP/PS1 and WT mice after the second trial of training in the memory acquisition series (trial A3, $3.95 \pm 0.45$ versus $2.67 \pm 0.37$; Figure $3 \mathrm{~A}$ ). This became more pronounced in the last acquisition trial A4 (3.79 \pm 0.44 versus $1.91 \pm 0.29)$ and in the recall trial, in which performance relied on the retrieval of newly formed memory traces (short-term memory) (trial R, $4.15 \pm 0.48$ versus $1.73 \pm 0.27$ ). Statistical analysis revealed a significant overall difference between the 2 groups $[\mathrm{F}(1,22)=13.53$; $P<0.01]$, and planned comparisons showed that the groups were significantly different in trials A3 $(P<0.05), \mathrm{A} 4$, and R $(P<0.001$ for both). Administration of rolipram for 3 weeks at $6-8$ weeks prior to the testing significantly reduced the gap between the 2 groups without affecting the performance of the WT animals (rolipram-treated $A P P / P S 1$ versus rolipram-treated WT animals: trial A3, $2.64 \pm 0.46$ versus $2.83 \pm 0.34$ errors; trial A4, $2.67 \pm 0.42$ versus $2.01 \pm 0.29$ errors; trial R, $2.41 \pm 0.36$ versus $2.14 \pm 0.31$ errors; $P>0.05$; Figure $3 \mathrm{~A})$. Statistical analysis revealed a strong effect of treatment in APP/ PS1 mice treated with rolipram compared with that of APP/PS1 animals treated with vehicle $[\mathrm{F}(1,22)=4.89, P<0.05]$, and planned comparisons showed that the groups were significantly different in trials $\mathrm{A} 3$ and $\mathrm{A} 4(P<0.05)$ and $\mathrm{R}(P<0.01)$. These data indicate that, in contrast to acute treatment with rolipram, 1 course of long-term treatment with the PDE4 inhibitor is capable of protecting spatial working memory in APP/PS1 mice.

To investigate rolipram effects on long-term memory, we examined reference memory with a Morris water maze, a widely used spatial learning test known to require hippocampal function (30, 31). APP/PS1 mice that had received vehicle 9-11 weeks prior to testing needed $21.02 \pm 1.54$ seconds to find the hidden platform after 6 sessions (Figure 3B) compared with $9.52 \pm 2.04$ seconds required by WT littermates [about $220 \%$ of the time needed by the vehicle-treated WT mice; $\mathrm{F}(1,20)=6.75 ; P<0.05$; planned comparisons showed that the groups were significantly different at the fifth and sixth sessions; $P<0.05$ and $P<0.01$, respectively] (19). When $A P P / P S 1$ mice were treated previously with rolipram they needed only $15.02 \pm 1.35$ seconds (about $157 \%$ of the time required by vehicle-treated WT mice). Rolipram-treated WT littermates needed $11.63 \pm 1.75$ seconds (about $122 \%$ of the time required by vehicle-treated WT mice). Statistical analysis revealed no significant difference in the overall performance of rolipramtreated APP/PS1 mice compared with that of vehicle-treated APP/
PS1 mice $[\mathrm{F}(1,22)=0.36, P>0.05$; Figure $3 \mathrm{~B}]$. However, planned comparisons of latency on each individual session revealed a significant difference between rolipram-treated APP/PS1 mice and vehicle-treated $A P P / P S 1$ mice in the sixth session $(P<0.05)$. Thus, we also assessed reference memory with the probe trial, another test of spatial long-term memory (32). This task is performed after the sixth hidden-platform session: the platform is removed from the water and the animals are allowed to search for 60 seconds. A mouse, knowing that the platform was in a certain position, will trawl repeatedly over that position looking for it. The mouse is thus indicating that it knows the position independently of such tactile cues as hitting the platform. The amount of time spent in each quadrant of the maze can be used to evaluate the spatial bias of an animal's search pattern. We found that vehicle-treated WT mice spent more time in the target quadrant (TQ), where the platform had been located during training $(36.28 \pm 2.24 \%$ of their time given), than in other quadrants [1-way ANOVA, $\mathrm{F}(3,44)=15.32$; $P<0.001$; Figure 3C). Planned comparisons confirmed that they spent significantly more time in the TQ than in the adjacent quadrant to the right (AR), in the adjacent quadrant to the left (AL), or in the opposite quadrant (OQ) $(P<0.001)$. We also found that rolipram improved the performance of the APP/PS1 mice (Figure $3 C)$. Rolipram-treated $A P P / P S 1$ mice remembered where the platform had been on the previous days. They searched significantly more in the quadrant where the platform had been located during training $(32.14 \pm 2.86 \%$ of their time given, or about $88 \%$ of the time used by vehicle-treated WT littermates) than in other quadrants $[\mathrm{F}(3,52)=3.76 ; P<0.05]$. Planned comparisons confirmed that they spent significantly more time in the TQ than in the AR, in the $\mathrm{AL}$, or in the $\mathrm{OQ}$ (TQ versus $\mathrm{AR}, P<0.05$; TQ versus $\mathrm{AL}$ and $\mathrm{OQ}, P<0.01)$. In contrast, vehicle-treated $A P P / P S 1$ mice could not retain the information and spent only $23.70 \pm 2.69 \%$ of the time in the TQ $(P>0.05)$, or about $65 \%$ of the time used by vehicle-treated WT littermates. Rolipram-treated WT mice remembered where the platform was the previous days and spent $36.99 \pm 1.82 \%$ of the time in the TQ $[\mathrm{F}(3,44)=23.21, P<0.001$; planned comparisons of TQ versus $\mathrm{AR}, \mathrm{AL}$, and $\mathrm{OQ}, P<0.001]$, or about $101 \%$ of the time used by vehicle-treated WT littermates. Student's $t$ test revealed a significant difference in the percent of time spent in the TQ by rolipram-treated $A P P / P S 1$ mice compared with that of vehicle-treated $A P P / P S 1$ mice $(P<0.05)$. No statistically significant difference was found in the percent of time spent in the TQ by rolipram-treated $A P P / P S 1$ mice compared with vehicle-treated and rolipram-treated WT mice $(P>0.05$ for both). A visible platform trial performed after the probe trials did not reveal any significant difference in the time to reach the platform among the 4 groups during the 4 sessions of the task (time at the fourth session: $14.7 \pm 4.23$ seconds for $A P P / P S 1$ mice treated with rolipram; $17.3 \pm 3.08 \mathrm{sec}-$ onds for $A P P / P S 1$ mice treated with vehicle; $17.5 \pm 4.97$ seconds for WT mice treated with rolipram; $14.0 \pm 2.45$ seconds for WT mice treated with vehicle; $P>0.05$; data not shown). Deficits in reference memory are characteristic of AD. The correction of similar deficits in the mouse model by rolipram suggests that PDE4 inhibitors have therapeutic potential in $\mathrm{AD}$.

To further analyze the functional changes that underlie the striking effects of rolipram on the behavioral performance of APP/PS1 mice, we examined synaptic function in hippocampi from the same mice. In contrast to 3-month-old double-transgenic mice, 7- to 8-month-old APP/PS1 animals show a reduction in synaptic strength (19). Seven- to eight-month-old WT mice treated with either vehicle 
A
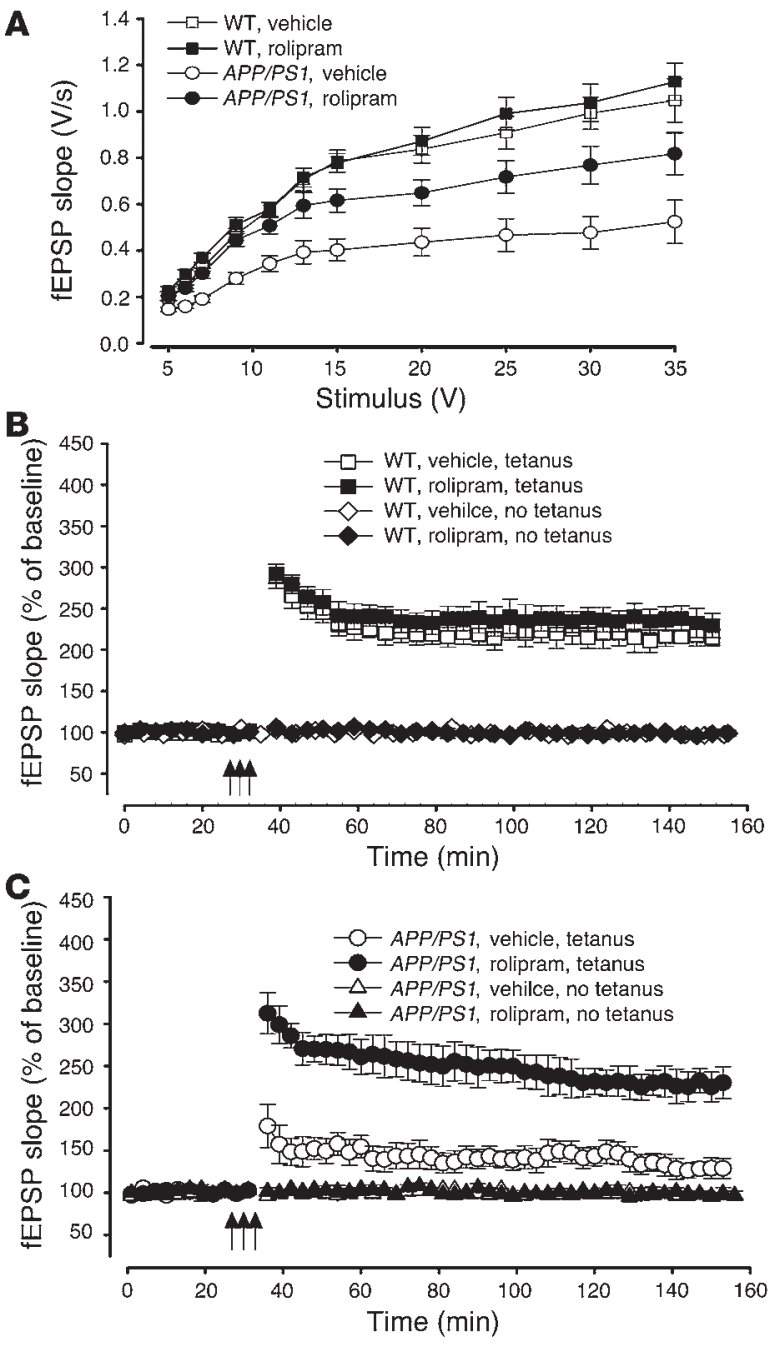

or rolipram had similar fEPSP slope values in response to a $35-\mathrm{V}$ stimulus [slope of the input-output curve in rolipram-treated WT mice, about $106 \%$ that of vehicle-treated WT mice: rolipram-treated WT mice, $1.12 \pm 0.08 \mathrm{~V} / \mathrm{s}$; vehicle-treated mice, $1.05 \pm 0.09 \mathrm{~V} / \mathrm{s}$; 2 -way ANOVA, $\mathrm{F}(1,20)=0.14 ; P>0.05$; Figure $4 \mathrm{~A}]$. Vehicle-treated $A P P / P S 1$ animals had a significantly lower response than did WT mice [about $49 \%$ that of vehicle-treated WT mice: $0.52 \pm 0.07 \mathrm{~V} / \mathrm{s}$; $\mathrm{F}(1,20)=14.73 ; P<0.001$; planned comparisons showed that the groups were significantly different at stimulus intensities between 7 and $35 \mathrm{~V} ; P<0.01]$. APP/PS1 animals that had been previously treated with rolipram had a significantly higher response than did vehicle-treated double-transgenic mice [about $78 \%$ that of vehicletreated WT mice: $0.82 \pm 0.09 \mathrm{~V} / \mathrm{s} ; \mathrm{F}(1,23)=13.64 ; P<0.01$; planned comparisons showed that the groups were significantly different between 7 and $35 \mathrm{~V} ; P<0.01]$. No statistically significant difference was found in the fEPSP slope values of rolipram-treated APP/PS1 mice compared with those of vehicle-treated and rolipram-treated WT mice $[F(1,23)=0.26 ; P>0.05]$. Similar results were obtained when the fEPSP slope were plotted versus the amplitude of the fiber afferent volley (data not shown).

Next, we tested the capacity of the CA3-CA1 connections to undergo potentiation. Seven- to eight-month-old WT mice showed similar amounts of potentiation whether treated with rolipram or

\section{Figure 4}

Daily injections of rolipram for 3 weeks in 3-month-old APP/PS1 mice reverse the BST and LTP impairments in hippocampal slices from the same mice at 7-8 months of age. (A) BST impairment in APP/PS1 animals is improved by previous treatment with rolipram $[F(1,23)=13.64, P<0.01]$. Rolipram does not affect BST in WT mice $[\mathrm{F}(1,20)=0.14, P>0.05]$. (B) Summary graph showing that rolipram does not affect L-LTP and baseline transmission in WT mice $[\mathrm{F}(1,22)=1.07, P>0.05]$. (C) Summary graph showing that rolipram abrogates L-LTP impairment in APP/PS1 mice without affecting basal neurotransmission $[F(1,23)=15.01, P<0.001]$. These experiments were interleaved with those of WT mice.

with vehicle [rolipram-treated mice showed about $111 \%$ that of vehicle-treated mice: rolipram-treated mice, $238.42 \pm 18.71 \%$ of baseline, $n=10$ slices from 10 mice, 8 males plus 2 females; vehicle-treated mice, $214.16 \pm 8.56 \%$ of baseline, $n=14$ slices from 12 mice, 10 males plus 2 females; $\mathrm{F}(1,22)=1.07 ; P>0.05$; Figure $4 \mathrm{~B}]$. L-LTP values recorded from slices obtained from APP/PS1 mice that had been previously treated with rolipram were similar to those of their WT littermates [about 104\% that of vehicle-treated WT mice: $224.27 \pm 18.21 \%$ of baseline at $120 \mathrm{~min}, n=13$ slices from 12 mice, 10 males plus 2 females; $\mathrm{F}(1,20)=2.41 ; P>0.05$ ] and were far greater than those of vehicle-treated APP/PS1 littermates [about $60 \%$ that of vehicle-treated WT mice: $130.50 \pm 10.71 \%$ of baseline, $n=12$ slices from 10 mice, 8 males plus 2 females; $\mathrm{F}(1,23)=15.01 ; P<0.001$; planned comparisons showed that the groups were significantly different at each time point after the tetanus, $P<0.001$; Figure $4 \mathrm{C}$ ]. No alteration was noted in the baseline transmission of the 4 groups of mice (Figure $4, B$ and C) in the absence of tetanus $(P>0.05)$.

Effects of rolipram on levels of brain $A \beta$ and CREB phosphorylation in APP/PS1 mice. Given the extensive and important physiological and behavioral effects of rolipram treatment in the doubletransgenic mice, we examined whether the treatment with the inhibitor affected $A \beta$ levels and amyloid burden, 2 hallmarks of AD. ELISA of extracts of cerebral cortex revealed no difference in $A \beta 40$ and $A \beta 42$ levels after 1 course of 3 weeks' treatment with rolipram at the age of 3 months in APP/PS1 mice that were sacrificed after the second round of behavioral testing at $7-8$ months of age (A $\beta 40$, about $107 \%$, and $A \beta 42$, about $95 \%$ that of vehicle-treated $A P P / P S 1$ mice; $A \beta 40$ and $A \beta 42$ values were $71.17 \pm 8.63$ and $79.21 \pm 7.50 \mathrm{pmol} / \mathrm{mg}$ protein, respectively, in rolipram-treated $A P P / P S 1$ mice, $n=17$, versus $66.07 \pm 12.09$ and $82.83 \pm 11.83 \mathrm{pmol} / \mathrm{mg}$ protein in vehicle-treated $A P P / P S 1$ mice, $n=10 ; \mathrm{A} \beta 42 / \mathrm{A} \beta 40$ ratios equal to $1.30 \pm 0.13$ in rolipramtreated double-transgenic mice and $1.32 \pm 0.08$ in vehicle-treated double-transgenic mice; $P>0.05$; see Supplemental Figure 2, A and B). No A $\beta$ was detected in WT littermates. Similar results were obtained by measurement of $A \beta$ levels and percentage of surface area covered by $A \beta$ immunoreactivity to measure plaque load in the hippocampus (data not shown). Thus, it is likely that rolipram does not interfere with $\mathrm{A} \beta$ production to produce its beneficial effects on learning and memory in the APP/PS1 mice.

As mentioned earlier, rolipram has a relatively short duration of action and is rapidly cleared from the body. Thus, a direct effect of the PDE4 inhibitor cannot be responsible for its long-term effects. To determine the mechanisms by which the inhibitor produces the long-term changes in synaptic physiology and behavior, we measured levels of CREB phosphorylation in rolipram-treated 


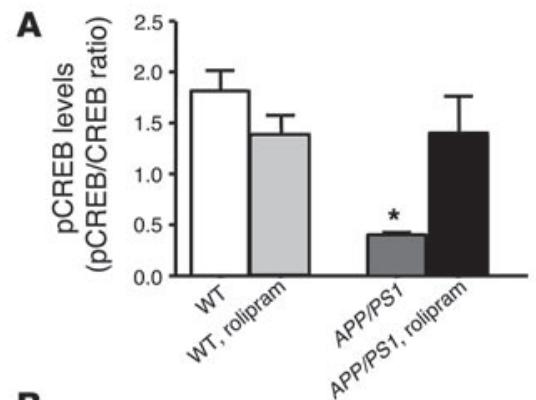

B
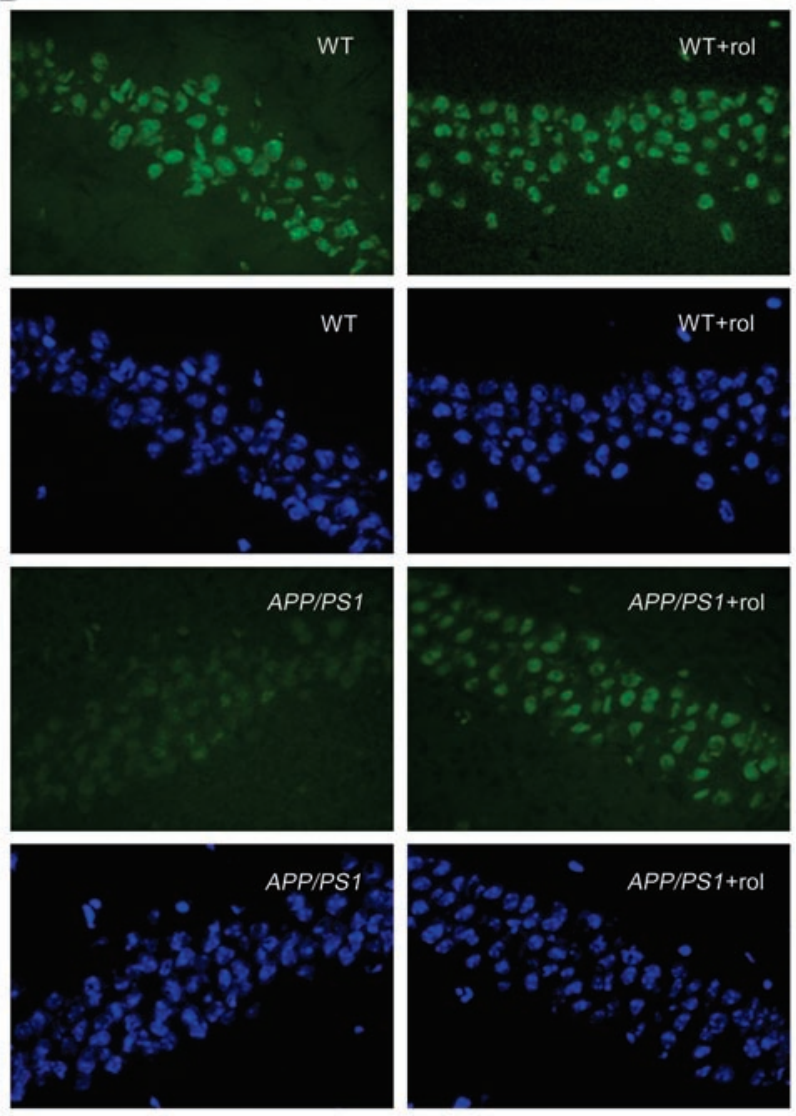

and vehicle-treated double-transgenic and WT mice. Western blot revealed a decrease in CREB phosphorylation in vehicle-treated APP/PS1 mice compared with vehicle-treated WT littermates. However, 1 course of 3 weeks of treatment with rolipram at the age of 3 months reestablished normal levels of CREB phosphorylation in 7- to 8-month-old transgenic animals. Rolipram did not affect levels of phosphorylated CREB (phospho-CREB) in WT mice $(P=0.02$, WT versus $A P P / P S 1 ; P=0.04, A P P / P S 1$ versus $A P P /$ $P S 1$ plus rolipram; $P>0.05$, WT versus $\mathrm{WT}$ plus rolipram and $A P P / P S 1$ plus rolipram; $n=20$; Figure $5 \mathrm{~A}$ ). Consistent with these results, immunohistological analysis of phospho-CREB revealed a decrease in CREB phosphorylation in the transgenic mice, which was returned to control levels by rolipram (Figure 5B). Thus, at the root of the long-term improvement in synaptic physiology and behavior there is a permanent increase in CREB phosphorylation in APP/PS1 mice that persists beyond the duration of the application of rolipram and its direct effect on PDE4. Moreover, this effect lasts at least until the age of 8 months, opening a new and

\section{Figure 5}

Daily injections of rolipram for 3 weeks in 3-month-old APP/PS1 mice reverse the decrease in CREB phosphorylation both in hippocampal extracts and in hippocampal slices from the same mice at 7-8 months of age. (A) Histogram showing that rolipram "rescues" the reduction in hippocampal phospho-CREB (pCREB), measured by Western blot, in APP/PS1 mice without increasing levels of CREB phosphorylation in WT mice. ${ }^{*} P<0.05$. (B) Examples of phospho-CREB staining (green) in the CA1 area of hippocampal sections from APP/PS1 and WT littermates, showing that rolipram (rol) abrogates the reduction in phospho-CREB in APP/PS1 mice without increasing levels of CREB phosphorylation in WT mice. Hoechst staining (blue) of the same sections shows that the neuronal population and the extent of cell death are not significantly different among the specimens.

important perspective for the use of PDE4 inhibitors in the treatment of the cognitive deficits in $\mathrm{AD}$ and other neurodegenerative diseases associated with elevated $\mathrm{A} \beta$.

\section{Discussion}

The data presented here show that treatment with rolipram can not only immediately counteract the inhibitory effects of high levels of $\mathrm{A} \beta$ on synaptic plasticity and contextual learning but also considerably delay the natural progression of the $A \beta$-induced synaptic and cognitive abnormalities, producing long-lasting neuronal modifications. Rolipram is a PDE4 inhibitor that is known to enhance learning and memory by increasing cAMP levels and stimulating the cAMP/PKA/CREB pathway, which is highly conserved across species, regulating olfactory memory in Drosophila (33) as well as hippocampus-dependent memory in mice $(22,34)$. We have recently shown that the PDE4 inhibitor is capable of reversing the inhibition of PKA and CREB both in cultured hippocampal neurons and in acute hippocampal slices that are exposed to sublethal levels of $A \beta 42$ (4). Thus, our results here confirm those findings and extend them to a transgenic animal model of $\mathrm{AD}$ that represents a more "physiological" approach than the exogenous application of $A \beta$. The strength of such an approach is the correlation of learning phenotypes with physiological and biochemical phenotypes, as evaluated by measurement of fEPSPs in slices or protein levels in tissue lysates.

A very important finding of our study here is the persistent effect of rolipram long after its administration has ceased. The PDE4 inhibitor ameliorates LTP, BST, and different forms of explicit learning deficits including associative, working, and reference memory defects, even 2 months after a 3 -week treatment period. Given rolipram's short half-life, it is likely that the persistent improvement in the behavior and synaptic responses of rolipram-treated $A P P / P S 1$ animals is due to stabilization of synaptic circuitry via alterations in gene expression (14). In agreement with this hypothesis, we were able to demonstrate a decrease in CREB phosphorylation in the transgenic mice, which was returned to control levels by rolipram (see Figure 5). CREB-dependent gene expression has been shown to underlie long-term memory formation in several vertebrate and invertebrate species, probably through the formation of new synaptic connections (23). A protein synthesis-dependent, rolipram-reinforced LTP with synaptic tagging has also been found in the CA1 hippocampal region (35), supporting the hypothesis that cAMP-dependent processes are directly involved in the synthesis of plasticity proteins. Indeed, several studies have already indicated that synaptic dysfunction 
may play a fundamental role in the early phases of $\mathrm{AD}$ (1). Thus, it is likely that both the formation of new synapses and the consolidation of old ones are involved in the long-term effects of rolipram treatment. It may be that impairment of the excitatory response at single synapses for an extended period of time by $A \beta(2-5)$ could lead to the progressive exclusion of those synapses that are not strengthened from the cellular network and to limited residual function of the hippocampus. Rolipram would interfere with the weakening of these synapses and protect them from consequences of the action of $A \beta$, leading to correct hippocampal function. In addition to these mechanisms, it is also legitimate to hypothesize that sustained increases in intracellular cAMP would induce proliferation and neurogenesis in the affected hippocampi (36). As a result, a greater number of mature neurons would be recruited by rolipram activity, while the increased proliferation would preserve the progenitor pool, thus acting to reestablish the equilibrium with the synaptic dysfunction produced by $\mathrm{A} \beta$.

The fact that APP/PS1 mice treated with rolipram showed markedly ameliorated synaptic and learning/memory deficits without any alteration in cortical or hippocampal $A \beta$ pathology $(A \beta$ levels and percentage of surface area covered by $A \beta$ deposits) suggests that a reduction in $A \beta$ production or deposition is not responsible for the improvements. Consistent with these findings, passive immunization with monoclonal anti-A $\beta$ ameliorated learning and memory performance without any alteration in cortical or hippocampal A $\beta$ burden in mice transgenic for the APP minigene driven by a PDGF promoter (PDAPP mice) (37). Moreover, correlation between $A \beta$ pathology and memory impairment is a point of contention both in $\mathrm{AD}$ patients (38) and in transgenic mouse models of AD (19). Alternatively, as pointed out previously (37), changes in the soluble pool of $A \beta(26)$, in the aggregation state of non-deposited $A \beta$, or in intraneuronal $A \beta$ (39-41) that could not be detected because of the accelerated phenotype of the APP/PS1 mice used in our experiments might have contributed to the beneficial effects of rolipram. Nonetheless, the effect of rolipram that we have reported here represents a potentially important mechanism for ameliorating the synaptic and behavioral deficits produced by $A \beta$.

PDE inhibitors are known to act through the CREB signaling pathway. Activation of this system has been shown to be potentially beneficial in conditions such as Rubinstein-Taybi syndrome (14), stroke (42), neurofibromatosis type 1 mental retardation $(43,44)$, and attention and mood disorders (45-47), and in agerelated memory loss (7). Moreover, caffeine, a compound with multiple actions including PDE inhibitory activity (48), reverses the memory disruption in a rat model of Parkinson disease obtained through intranigral injection of 1-methyl-4-phenyl1,2,3,6-tetrahydropyridine (MPTP) (49). Caffeine has also been shown to improve inhibitory avoidance memory task in normal mice $(50,51)$. The findings presented here extend these observations to animal models of $\mathrm{AD}$, indicating for the first time to our knowledge that inhibition of PDE activity might effectively counteract learning and memory defects in $\mathrm{AD}$.

The therapies for AD that are currently in use include augmentation of the cholinergic system by inhibition of acetylcholinesterases or, more recently, the use of NMDA antagonists that may act by blocking glutamate neurotoxicity. These agents have a limited efficacy and only the latter appears to have an even modest effect on the course of the disease. A major effort is underway to decrease the $A \beta$ load in the brain either by the use of agents that block the secretases that process $A P P$ to $\mathrm{A} \beta$ or by the use of treatments, such as immu- nization with $A \beta$, that appear to augment the removal of $A \beta$ from the brain (52). Animal studies have demonstrated that the neuritic dystrophy that develops in animals that overproduce $A \beta$ can be reversed by immunization (by $A \beta$ antibodies) that removes $A \beta$ from the brain (53). Unfortunately, human trials of an $A \beta$ vaccine had to be terminated because of encephalitic complications in some of the patients $(54,55)$. Rolipram and other PDE4 inhibitors represent a new approach to treatment that appears to make the synapse more robust and resistant to the effects of $A \beta$. Our results suggest not only that is rolipram capable of stopping memory degradation in the presence of $A \beta$ accumulation but also that it may improve function in a brain that, as in the case of the 3-month-old doubletransgenic mouse, has already lost function. Rolipram is marketed in several countries as an antidepressant. Its principal side effects are dose-related nausea and emesis (56). Novel PDE4 inhibitors in which the side effects have been minimized are being developed by the pharmaceutical industry. It remains to be seen if these newer inhibitors can readily enter the brain and if they are as effective as rolipram (57). Because our CREB phosphorylation data strongly support the idea that rolipram acts by increasing intracellular cAMP levels, agents that increase the synthesis of cAMP by stimulating adenylate cyclase would also be likely to give similar results.

Further studies are needed to determine how long the improvement in cognitive function will persist after a single course of treatment and whether better and longer-lasting results can be obtained with either continuous treatment or successive courses of treatment. Studies are also underway to determine the effect of rolipram treatment on the synaptic and dendritic architecture of the transgenic animals compared with that of untreated littermates. In considering possible applications of rolipram and PDE4 inhibitors for the treatment of $\mathrm{AD}$, it is significant that the observed trophic effects are not limited to the initial phase of synaptic and behavioral changes in the young animal and that they are actually proportionally larger in the older mice. This widens the possible therapeutic window of this class of compounds, not limiting it to the initial phases of the disease. Therefore, the findings highlighted in our study here provide a new and promising perspective on the treatment of $\mathrm{AD}$ and related dementias and add a new class of drugs to the treatments already available to fight this devastating illness.

\section{Methods}

Transgenic mouse production. All animal studies were performed according to protocols examined and approved by the Animal Use and Care Committee of Columbia University. Hemizygous transgenic (HuAPP695SWE)2576 mice expressing mutant human APP (K670N,M671L) (58) were crossed with hemizygous PS1 mice that express mutant human PS1 (M146V; line 6.2) (59). The offspring, double-transgenic mice overexpressing APP/PS1, were compared with their WT littermates so that age and background strain were comparable. To identify the genotype of the animals, we used DNA extracted from tail tissue $(58,59)$.

Slice preparation. Mice were decapitated and their hippocampi were removed. Transverse hippocampal slices $400 \mu \mathrm{m}$ in thickness were maintained in an interface chamber at $29^{\circ} \mathrm{C}$ as described previously (4). They were perfused with saline solution (124.0 mM NaCL, $4.4 \mathrm{mM} \mathrm{KCL}, 1.0 \mathrm{mM}$ $\mathrm{Na}_{2} \mathrm{HPO}_{4}, 25.0 \mathrm{mM} \mathrm{NaHCO}_{3}, 2.0 \mathrm{mM} \mathrm{CaCL}_{2}, 2.0 \mathrm{mM} \mathrm{MgSO}_{4}$, and $10 \mathrm{mM}$ glucose) continuously bubbled with $95 \% \mathrm{O}_{2}$ and $5 \% \mathrm{CO}_{2}$. Slices were permitted to recover from cutting for at least 90 minutes before recordings.

Electrophysiological recordings. The fEPSPs were recorded from the CA1 region of the hippocampus by placement of both the stimulating and the recording electrodes in the CA1 stratum radiatum, as described previously 
(4). BST was assayed by plotting of the stimulus voltage (V) against slopes of fEPSP to generate input-output relations or by plotting of the peak amplitude of the fiber volley against the slope of the fEPSP to generate input-output relations. LTP was induced using theta-burst stimulation (4 pulses at $100 \mathrm{~Hz}$, with the bursts repeated at $5 \mathrm{~Hz}$, and each tetanus including 3 10-burst trains separated by 15 seconds). Each point of the graphs represents the average of 5 successive events. Rolipram or vehicle in $0.1 \%$ DMSO was added to the bath solution for 20 minutes prior to the induction of LTP. In a separate series of experiments, kynurenate (1 mM), an NMDA receptor antagonist, was added to slices from APP/PS1 mice and WT littermates during the dissection and for 1 hour after the dissection to test whether slice preparation itself could exacerbate excitotoxicity in transgenic slices and thereby lead to the observed deficits in synaptic function. The presence of kynurenate did not prevent the impairment of BST and LTP in slices from transgenic mice (3-month-old WT mice, $n=3$; 3-month-old APP/PS1 mice, $n=3$; 7- to 8-month-old WT mice, $n=4$; 7 - to 8-month-old APP/PS1 mice, $n=4 ; P>0.05)$.

Drug administration. Three-month-old APP/PS1 and WT mice were evenly separated into 4 groups: $A P P / P S 1$ mice treated with vehicle, $A P P / P S 1$ mice treated with rolipram, WT mice treated with vehicle, and WT mice treated with rolipram. Rolipram was administrated either acutely or for 1 course of long-term treatment. For assessment of the short-term effects of rolipram, the drug was given at a concentration of $0.03 \mathrm{mg} / \mathrm{kg}$ via s.c. injection 30 minutes before the behavioral tests. This dose yields concentrations between $0.06 \mu \mathrm{M}$ and $0.2 \mu \mathrm{M}$ in the brain 30 minutes after treatment (60). For assessment of long-term effects, rolipram was given daily by s.c. injection at a concentration of $0.03 \mathrm{mg} / \mathrm{kg}$ for 3 weeks and then treatment was stopped for 6-8 weeks prior to behavioral testing. Contextual and cued fear conditioning was performed for 3 days. Then, mice were tested for 3 weeks in the radial-arm water maze, followed by 1 week of testing in the classic water maze. Finally, the animals were sacrificed for electrophysiological recordings. In a separate series of experiments, we tested which doses of rolipram could lead to the observed amelioration of synaptic and behavioral deficits in APP/PS1 mice. Both transgenic $(n=4)$ and WT $(n=4)$ littermates were injected s.c. daily with rolipram at a concentration of $0.015 \mathrm{mg} / \mathrm{kg}$ or $0.06 \mathrm{mg} / \mathrm{kg}$ for 3 weeks and then, as they reached the age of 8 months, they were subjected to behavioral tasks in the following sequence: fear conditioning, radial-arm water maze, and Morris maze. Finally, they were sacrificed for measurement of BST and LTP. Both doses of rolipram produced the beneficial effect both on explicit learning and synaptic physiology in transgenic animals $(P>0.05)$.

Contextual and cued fear conditioning. Our conditioning chamber was located inside a sound-attenuating box $(72 \mathrm{~cm} \times 51 \mathrm{~cm} \times 48 \mathrm{~cm})$. A clear Plexiglas window $(2 \mathrm{~cm} \times 12 \mathrm{~cm} \times 20 \mathrm{~cm})$ allowed the experimenter to film the mouse performance with a camera placed on a tripod and connected to Freezeframe software (MED Associates Inc.). To provide background white noise $(72 \mathrm{~dB})$, a single computer fan was installed in 1 of the sides of the sound-attenuating chamber. The conditioning chamber $(33 \mathrm{~cm} \times 20 \mathrm{~cm}$ $\times 22 \mathrm{~cm}$ ) was made of transparent Plexiglas on 2 sides and metal on the other 2. One of the metal sides had a speaker and the other had a 24-V light. The chamber had a 36-bar insulated shock grid floor. The floor was removable and after each use we cleaned it with $75 \%$ ethanol and then with water. Only 1 animal at a time was present in the experimentation room. The other mice remained in their home cages. Sensory perception of the shock was determined through threshold assessment. A sequence of single foot shocks was delivered to animals placed on the same electrified grid used for fear conditioning. Initially, a $0.1-\mathrm{mA}$ shock was delivered for 1 second. At 30 -second intervals the shock intensity was increased by $0.1 \mathrm{~mA}$ to $0.7 \mathrm{~mA}$, and animal behavior was evaluated for the first visible response to the shock (flinch), the first extreme motor response (run/jump), and the first vocal- ized distress (scream). Threshold to flinching, jumping, and screaming was quantified for each animal by averaging of the shock intensity at which each animal manifested a behavioral response of that type to the foot shock. For the cued and contextual conditioning experiments, mice were placed in the conditioning chamber for 2 minutes before the onset of a discrete tone (CS) (a sound that lasted 30 seconds at $2,800 \mathrm{~Hz}$ and $85 \mathrm{~dB}$ ). In the last $2 \mathrm{sec}-$ onds of the CS, mice were given a foot shock (US) of $0.50 \mathrm{~mA}$ for 2 seconds through the bars of the floor. After the CS/US pairing, the mice were left in the conditioning chamber for another 30 seconds and then were placed back in their home cages. "Freezing" behavior, defined as the absence of all movement except for that necessitated by breathing, was assigned scores using Freezeview software (MED Associates Inc.). For evaluation of contextual fear learning, freezing was measured for 5 (consecutive) minutes in the chamber in which the mice were trained at 24 hours after training. For evaluation of cued fear conditioning, after contextual testing, mice were placed in a novel context (triangular cage with smooth flat floor and with vanilla odorant) for 2 minutes (pre-CS test), after which they were exposed to the CS for 3 minutes (CS test), and freezing was measured.

Radial-arm water maze. The task has been described previously $(19,28)$. Each day of testing included 4 consecutive trials (A1-A4) and a fifth trial (R) that was 30 minutes after the fourth trial. The first 4 trials tested acquisition of the task, while the fifth trial tested retention memory (short-term memory). Each trial lasted 1 minute. Errors were counted when the mouse went to an arm without platform or took more than 20 seconds to enter any arm of the maze. The number of errors in each trial in the last 3 days of testing was averaged and used for statistical analysis.

Morris water maze. The task has been described previously (19). Mice were trained in 2 daily sessions ( 4 hours apart), each consisting of 3 trials ( 1 minute each), for 3 days. Time required to reach the hidden platform (latency) was recorded. The training was followed by 4 probe trials with the platform moved to test the retention of the spatial memory. The maze was divided into 4 quadrants. The percent of time spent in the quadrant that previously contained the platform was recorded and analyzed with a video tracking system (HVS 2020; HVS Image). After the probe trials, visible platform training was used to test the visual, motor, and motivation skills of the mice. Both time to reach the platform and swimming speed were recorded and analyzed with a video tracking system (HVS-2020, HVS Image, UK).

Quantification of amyloid peptides by ELISA. The technique for the measurement of the $A \beta$ levels has been described previously (19). Briefly, levels of human brain $A \beta$ were determined by sandwich ELISA of hemibrains homogenized in sucrose buffer and extracted in formic acid. ELISA signals are reported as the mean \pm SEM of the results of 2 replica wells in picomoles of $A \beta$ per milligram of protein (determined with the BCA Protein Assay Reagent Kit).

Immunoperoxidase staining for A $\beta$ plaques. Immunostaining of plaques containing both fibrillar and diffuse $A \beta$ has been described previously (19). Briefly, brain slices were incubated for 1 hour at room temperature with monoclonal antibody 4G8 (Signet Laboratories Inc.). The secondary antibody was biotinylated anti-mouse IgG. Sections were incubated in avidin:biotinylated enzyme complex reagent and were developed with $3,3^{\prime}$-diaminobenzidine substrate and mounted on slides. The percentage of surface area covered by $\mathrm{A} \beta$ immunoreactivity was used for measurement of plaque load. Two regions were analyzed: an area of parietal cortex comprising layers I-VI and an area of the hippocampal formation comprising the stratum oriens, pyramidal layer, stratum radiatum, and dentate gyrus.

Western blot. This technique has been described previously (4). For the immunostaining protocol, hippocampi from brains of sacrificed mice were used for electrophysiological analysis or were frozen in liquid nitrogen and processed for Western blot analysis of protein levels. Tissues were homogenized with disposable Dounce homogenizers (Kontes glass company) in 
radioimmunoprecipitation assay buffer containing protease inhibitors and phenylmethylsulfonylfluoride; the temperature was maintained at $4^{\circ} \mathrm{C}$ throughout the whole procedure. The resulting homogenate was centrifuged twice at $10,000 \mathrm{~g}$ for 10 minutes at $4^{\circ} \mathrm{C}$ and the supernatant was assayed for protein content and separated by $8 \%$ PAGE. Protein was blotted onto a nitrocellulose membrane and probed with antibodies against phospho-CREB (Upstate Biotechnology), CREB, and ERK1 (Santa Cruz Biotechnology). Blots were repeated twice, scanned, and analyzed with NIH Image software v.1.63. Phospho-CREB levels were measured as phosphoCREB/CREB ratios normalized using ERK1 protein levels.

Immunohistochemistry. Brains from sacrificed mice were dissected; one hemisphere was used for electrophysiological studies while the other was frozen on liquid nitrogen and used for immunostaining. Sections $4 \mu \mathrm{m}$ in thickness were obtained with a cryostat and were subsequently fixed in $4 \%$ paraformaldehyde/ $1 \times$ PBS, washed 3 times in $1 \times$ PBS, treated with $0.2 \%$ Triton X-100 for 30 minutes at room temperature, washed 3 times in $1 \times$ PBS again, and incubated in $5 \%$ goat serum for 30 minutes. Sections were then incubated overnight at $4{ }^{\circ} \mathrm{C}$ with primary antibody (rabbit polyclonal anti-phospho-CREB from Upstate Biotechnology, diluted 1:100 in 5\% goat serum). After 3 washes with $1 \times$ PBS (10 minutes each), slices were incubated for 1 hour at room temperature with the secondary antibody (goat anti-rabbit labeled with Alexa Fluor 488, diluted 1:4,000 in 5\% goat serum) and Hoechst 33258 dye (1:1,000 dilution), washed again 3 times, mounted, and examined with a fluorescence microscope (Nikon Eclipse E600) using $\times 20$ and $\times 60$ objectives. Analysis of images was also performed using NIH Image software (v.1.63). The specificity of the immunofluorescence was confirmed by omission of the primary antibody, which resulted in a significant reduction in fluorescence intensity.

Statistics. For all experiments mice were coded to "blind" investigators with respect to genotype and treatment. Data were expressed as mean \pm SEM.
Data were analyzed by Student's $t$ test (pairwise comparisons) or ANOVA with repeated measures (multiple comparisons). Planned comparisons were used for post-hoc analysis. Western blot data were analyzed using an unpaired $t$ test with Welch's correction. Results from male and female mice were pooled together.

\section{Acknowledgments}

We thank Karen Hsiao-Ashe (University of Minnesota and Mayo Clinic, Rochester, Minnesota, USA) for providing the APP mice, Karen Duff(Nathan Kline Institute and New York University School of Medicine) for providing the PS1 mice, Rusiko Bourtchouladze (Helicon Therapeutics Inc.) for helpful discussion and comments, Marc Mercken (Johnson and Johnson Pharmaceutical Research and Development, Janssen Pharmaceutica) for the ELISA antibodies, and Fortunato Battaglia (Nathan Kline Institute and New York University School of Medicine) for assistance with the electrophysiological experiments. This work was supported by New York State Institute for the Study of Aging, the Alzheimer's Association, and NIH.

Received for publication July 27, 2004, and accepted in revised form September 21, 2004.

Address correspondence to: Ottavio Arancio or Michael Shelanski, Department of Pathology, Columbia University, 630 West 168th Street, New York, New York 10032, USA. Phone: (212) 342-5527; Fax: (212) 342-5524; E-mail: oa1@columbia.edu (O. Arancio). Phone: (212) 305-3300; Fax: (212) 305-5498; E-mail: mls7@columbia.edu (M. Shelanski).

Bing Gong and Ottavio V. Vitolo contributed equally to this work.
1. Masliah, E. 1995. Mechanisms of synaptic dysfunction in Alzheimer's disease. Histol. Histopathol. 10:509-519.

2. Cullen, W.K., Suh, Y.H., Anwyl, R., and Rowan, M.J. 1997. Block of LTP in rat hippocampus in vivo by beta-amyloid precursor protein fragments. Neuroreport. 8:3213-3217.

3. Itoh, A., et al. 1999. Impairments of long-term potentiation in hippocampal slices of beta-amyloidinfused rats. Eur. J. Pharmacol. 382:167-175.

4. Vitolo, O.V., et al. 2002. Amyloid beta-peptide inhibition of the PKA/CREB pathway and long-term potentiation: reversibility by drugs that enhance cAMP signaling. Proc. Natl. Acad. Sci. U. S. A. 99:13217-13221.

5. Walsh, D.M., et al. 2002. Naturally secreted oligomers of amyloid beta protein potently inhibit hippocampal long-term potentiation in vivo. Nature. 416:535-539.

6. Bliss, T.V., and Collingridge, G.L. 1993. A synaptic model of memory: long-term potentiation in the hippocampus. Nature. 361:31-39.

7. Barad, M. 2003. Later developments: molecular keys to age-related memory impairment. Alzheimer Dis. Assoc. Disord. 17:168-176.

8. Zhang, H.T., Crissman, A.M., Dorairaj, N.R., Chandler, L.J., and O'Donnell, J.M. 2000. Inhibition of cyclic AMP phosphodiesterase (PDE4) reverses memory deficits associated with NMDA receptor antagonism. Neuropsychopharmacology. 23:198-204.

9. Zhang, H.T., and O'Donnell, J.M. 2000. Effects of rolipram on scopolamine-induced impairment of working and reference memory in the radialarm maze tests in rats. Psychopharmacology (Berl.). 150:311-316.

10. Imanishi, T., et al. 1997. Ameliorating effects of rolipram on experimentally induced impairments of learning and memory in rodents. Eur. J. Pharmacol. 321:273-278.

11. Zhang, H.T., et al. 2004. Inhibition of the phosphodiesterase 4 (PDE4) enzyme reverses memory deficits produced by infusion of the MEK inhibitor U0126 into the CA1 subregion of the rat hippocampus. Neuropsychopharmacology. 29:1432-1439.

12. Barad, M., Bourtchouladze, R., Winder, D.G., Golan, H., and Kandel, E. 1998. Rolipram, a type IV-specific phosphodiesterase inhibitor, facilitates the establishment of long-lasting long-term potentiation and improves memory. Proc. Natl. Acad. Sci. U. S. A. 95:15020-15025.

13. Nagakura, A., Niimura, M., and Takeo, S. 2002. Effects of a phosphodiesterase IV inhibitor rolipram on microsphere embolism-induced defects in memory function and cerebral cyclic AMP signal transduction system in rats. Br. J. Pharmacol. 135:1783-1793.

14. Bourtchouladze, R., et al. 2003. A mouse model of Rubinstein-Taybi syndrome: defective longterm memory is ameliorated by inhibitors of phosphodiesterase 4. Proc. Natl. Acad. Sci. U. S. A. 100:10518-10522.

15. Nicholson, C.D. 1990. Pharmacology of nootropics and metabolically active compounds in relation to their use in dementia. Psychopharmacology (Berl.). 101:147-159.

16. Ramos, B.P., et al. 2003. Dysregulation of protein kinase A signaling in the aged prefrontal cortex: new strategy for treating age-related cognitive decline. Neuron. 40:835-845.

17. Arendash, G.W., et al. 2001. Progressive, age-related behavioral impairments in transgenic mice carrying both mutant amyloid precursor protein and presenilin-1 transgenes. Brain Res. 891:42-53.

18. Battaglia, F., et al. 2003. Calpain inhibitors, a treat- ment for Alzheimer's disease: position paper. J. Mol. Neurosci. 20:357-362.

19. Trinchese, F., et al. 2004. Progressive age-related development of Alzheimer-like pathology in APP/ PS1 mice: early impairment of long-term potentiation and short-term memory associated with amyloid-beta production and plaque deposition. Ann. Neurol. 55:801-814.

20. Krause, W., and Kuhne, G. 1988. Pharmacokinetics of rolipram in the rhesus and cynomolgus monkeys, the rat and the rabbit. Studies on species differences. Xenobiotica. 18:561-571.

21. Phillips, R., and LeDoux, J. 1992. Differential contribution of amygdala and hippocampus to cued and contextual fear conditioning. Behav. Neurosci. 106:274-285.

22. Bourtchuladze, R, et al. 1994. Deficient long-term memory in mice with a targeted mutation of the cAMP-responsive element-binding protein. Cell. 79:59-68.

23. Tully, T., Bourtchouladze, R., Scott, R., and Tallman, J. 2003. Targeting the CREB pathway for memory enhancers. Nat. Rev. Drug Discov. 2:267-277.

24. Dineley, K.T., Xia, X., Bui, D., Sweatt, J.D., and Zheng, H. 2002. Accelerated plaque accumulation, associative learning deficits, and up-regulation of alpha 7 nicotinic receptor protein in transgenic mice co-expressing mutant human presenilin 1 and amyloid precursor proteins. J. Biol. Chem. 277:22768-22780.

25. Corcoran, K.A., Lu, Y., Turner, R.S., and Maren, S. 2002. Overexpression of hAPPswe impairs rewarded alternation and contextual fear conditioning in a transgenic mouse model of Alzheimer's disease. Learn. Mem. 9:243-252.

26. Morgan, D., et al. 2000. A beta peptide vaccination prevents memory loss in an animal model of Alzheimer's disease. Nature. 408:982-985. 
27. Lustbader, J.W., et al. 2004. ABAD directly links Abeta to mitochondrial toxicity in Alzheimer's disease. Science. 304:448-452.

28. Petrone, A., et al. 2003. Receptor protein tyrosine phosphatase alpha is essential for hippocampal neuronal migration and long-term potentiation. EMBO J. 22:4121-4131.

29. Diamond, D.M., Park, C.R., Heman, K.L., and Rose, G.M. 1999. Exposing rats to a predator impairs spatial working memory in the radial arm water maze. Hippocampus. 9:542-552.

30. Morris, R., Garrud, P., Rawlins, J., and O'Keefe, J. 1982. Place navigation impaired in rats with hippocamal lesions. Nature. 297:681-683.

31. Sutherland, R.J., Kolb, B., and Whishaw, I.Q. 1982. Spatial mapping: definitive disruption by hippocampal or medial frontal cortical damage in the rat. Neurosci. Lett. 31:271-276.

32. Schenk, F., and Morris, R.G. 1985. Dissociation between components of spatial memory in rats after recovery from the effects of retrohippocampal lesions. Exp. Brain Res. 58:11-28.

33. Yin, J.C., et al. 1994. Induction of a dominant negative CREB transgene specifically blocks long-term memory in Drosophila. Cell. 79:49-58.

34. Bach, M.E., et al. 1999. Age-related defects in spatial memory are correlated with defects in the late phase of hippocampal long-term potentiation in vitro and are attenuated by drugs that enhance the cAMP signaling pathway. Proc. Natl. Acad. Sci.U.S. A. 96:5280-5285.

35. Navakkode, S., Sajikumar, S., and Frey, J.U. 2004. The type IV-specific phosphodiesterase inhibitor rolipram and its effect on hippocampal long-term potentiation and synaptic tagging. J. Neurosci. 24:7740-7744.

36. Nakagawa, S., et al. 2002. Regulation of neurogenesis in adult mouse hippocampus by cAMP and the cAMP response element-binding protein. J. Neurosci. 22:3673-3682.

37. Dodart, J.C., et al. 2002. Immunization reverses memory deficits without reducing brain Abeta burden in Alzheimer's disease model. Nat. Neurosci.
5:452-457.

38. Iwatsubo, T., Mann, D.M., Odaka, A., Suzuki, N., and Ihara, Y. 1995. Amyloid beta protein (A beta) deposition: A beta 42(43) precedes A beta 40 in Down syndrome. Ann. Neurol. 37:294-299.

39. Oddo, S., et al. 2003. Triple-transgenic model of Alzheimer's disease with plaques and tangles: intracellular Abeta and synaptic dysfunction. New ron. 39:409-421.

40. LaFerla, F.M., Troncoso, J.C., Strickland, D.K., Kawas, C.H., and Jay, G. 1997. Neuronal cell death in Alzheimer's disease correlates with apoE uptake and intracellular $\mathrm{A} \beta$ stabilization. J. Clin. Invest. 100:310-320

41. Gouras, G.K., et al. 2000. Intraneuronal Abeta 42 accumulation in human brain. Am. J. Pathol. 156:15-20.

42. Dragunow, M. 2004. CREB and neurodegeneration. Front. Biosci. 9:100-103.

43. Weeber, E.J., and Sweatt, J.D. 2002. Molecular neurobiology of human cognition. Neuron. 33:845-848.

44. Tong, J., Hannan, F., Zhu, Y., Bernards, A., and Zhong, Y. 2002. Neurofibromin regulates $G$ protein-stimulated adenylyl cyclase activity. Nat. Neurosci. 5:95-96.

45. Andersen, S.L., Arvanitogiannis, A., Pliakas, A.M., LeBlanc, C., and Carlezon, W.A., Jr. 2002. Altered responsiveness to cocaine in rats exposed to methylphenidate during development. Nat. Neurosci. 5:13-14.

46. Perez, J., et al. 2000. Abnormalities of cAMP signaling in affective disorders: implication for pathophysiology and treatment. Bipolar Disord. 2:27-36.

47. Einat, H., et al. 2003. The role of the extracellular signal-regulated kinase signaling pathway in mood modulation. J. Neurosci. 23:7311-7316.

48. Nehlig, A., Daval, J.L., and Debry, G. 1992. Caffeine and the central nervous system: mechanisms of action, biochemical, metabolic and psychostimulant effects. Brain Res. Brain Res. Rev. 17:139-170.

49. Gevaerd, M.S., Takahashi, R.N., Silveira, R., and Da Cunha, C. 2001. Caffeine reverses the memory disruption induced by intra-nigral MPTP-injection in rats. Brain Res. Bull. 55:101-106.
50. Angelucci, M.E., et al. 1999. The effect of caffeine in animal models of learning and memory. Eur. J. Pharmacol. 373:135-140.

51. Castellano, C. 1976. Effects of caffeine on discrimination learning, consolidation, and learned behavior in mice. Psychopharmacology (Berl.). 48:255-260.

52. Schenk, D., et al. 1999. Immunization with amyloidbeta attenuates Alzheimer-disease-like pathology in the PDAPP mouse. Nature. 400:173-177.

53. Lombardo, J.A., et al. 2003. Amyloid-beta antibody treatment leads to rapid normalization of plaque-induced neuritic alterations. J. Neurosci. 23:10879-10883

54. Ferrer, I., Boada Rovira, M., Sanchez Guerra, M.L., Rey, M.J., and Costa-Jussa, F. 2004. Neuropathology and pathogenesis of encephalitis following amyloid-beta immunization in Alzheimer's disease. Brain Pathol. 14:11-20.

55. Nicoll, J.A., et al. 2003. Neuropathology of human Alzheimer disease after immunization with amyloidbeta peptide: a case report. Nat. Med. 9:448-452.

56. Hebenstreit, G.F., et al. 1989. Rolipram in major depressive disorder: results of a double-blind comparative study with imipramine. Pharmacopsychiatry. 22:156-160.

57. Dal Piaz, V., and Giovannoni, M.P. 2000. Phosphodiesterase 4 inhibitors, structurally unrelated to rolipram, as promising agents for the treatment of asthma and other pathologies. Eur. J. Med. Chem. 35:463-480.

58. Hsiao, K., et al. 1996. Correlative memory deficits, Abeta elevation, and amyloid plaques in transgenic mice. Science. 274:99-102.

59. Duff, K., et al. 1996. Increased amyloid-beta42(43) in brains of mice expressing mutant presenilin 1 . Nature. 383:710-713.

60. Barad, M., Bourtchouladze, R., Winder, D.G., Golan, H., and Kandel, E. 1998. Rolipram, a type IV-specific phosphodiesterase inhibitor, facilitates the establishment of long-lasting long-term potentiation and improves memory. Proc. Natl. Acad. Sci. U. S. A. 95:15020-15025. 